\title{
The Effect of Wikis and Face-to-Face Collaborative Writing on the Writing Performance and Self- regulated Learning Skills among EFL Students
}

\section{Dr. Mona Salem Mahmoud Za'za' \\ Dr. Somia Ali Abdel Wareth Ahmed}

\begin{abstract}
Writing is a complex process that requires pre-writing activities such as brainstorming, word mapping, outlining, drafting, editing and revising. The process is facilitated by group collaboration in the different writing stages. Wikis, as one of the Web 2.0 social networking tools, are web sites, the content of which can be edited by visitors to the site, allowing users to easily create and edit pages collaboratively. This study aims at investigating the effect of using wikis and face -to- face collaborative writing on the writing performance and self- regulated learning skills among EFL college students. The study comprises 66 female participants enrolled in Writing 4, an advanced writing course, at Level 4 in the College of Education at Dhahran Al-Janoub, King Khaled University, Saudi Arabia. The experimental group $(n=34)$ used wikis for collaborative essay writing while the control group $(n=32)$ used face-to-face collaboration. Results of the study revealed that students using wikis as collaborative writing tools outperformed those using face-to-face collaborative writing in essay writing performance. Besides, they outperformed them in selfregulated learning skills. The study gives implications on the potentials that wikis hold for the teaching of EFL and the area of writing skill.
\end{abstract}

Key words: e-learning, wikis, collaborative writing, self-regulated learning Introduction

Writing is one of the important language skills that facilitates communication and connections among members of families, communities, and nations; promotes self-expression and personal development; and allows us to gather, refine, share, and preserve knowledge and understandings. Writing is a complex process that requires pre-writing activities such as brainstorming, word mapping, outlining, drafting, editing and revising. The process is facilitated by group collaboration in the different writing stages. With Web 2.0 tools which highly surmount users' participations, such as blogs, wikis, podcasts, social bookmarking, photo sharing, instant messaging, VolP applications, RSS feeds, mashups, etc, the possibilities for communication and collaboration have proliferated (Karasavvidis, 2010).

Wikis, as one of the Web 2.0 social networking tools, have been widely and increasingly integrated into second and foreign language instruction to promote collaborative writing. Wikis are popular web sites that allow users to create, publish and share web contents without much programming skill (Chang et.al.,

\section{5}


2010). "A wiki is a web site, the content of which can be edited by visitors to the site, allowing users to easily create and edit pages collaboratively" (Su and Beaumont, 2010:417) .

Wikis are a form of asynchronous computer-mediated communication in which all participants have equal chances for participating in planning, drafting, editing and revising. They develop linguistic skills as participants use the target language to interact, negotiate, and construct meaning. Wikis also enhance collaborative skills as teamwork, consensus building, collaborative effort, and individual accountability which are essential to the effective use of wikis. The wiki is a catalyst in language skill development (MartinezCarrillo \& Pentikousis, 2008). Wikis are an effective tool to support collaborative learning and knowledge sharing. Wikis also make use of Vygotskian socio-cultural theories of learning to the collective learning of a language. Wikis open the possibility of capturing more deeply the communicative relationships between the students without requiring them to be in the same place (Allsop, 2011).

Karasavvidis (2010) explains that wikis allow collaborative creation of content. They do not need a specific operating system or application software. Besides, they do not require advanced computer and internet skills. According to Allsop (2011) and Karasavvidis (2010), wikis allow their users the ability to compare previous versions of a page, track who edited what and when. Furthermore, a wiki can involve different kinds of work. It can involve individual work (e.g. writing a page), collaboration (i.e. the shared construction of text), communication (i.e. a threaded discussion on a given topic), and evaluation (i.e. peer review of the texts authored). Its added value is manifested in that, by definition, it allows for the creation of dynamic text which simultaneously represents both the finished product and the process of creating it (Karasavvidis, 2010). A user can link keywords within a document or a number of documents, which allows the growth of wiki pages, while editing privileges may also be extended to all users or restricted to selected users to the wiki sites (Chang, 2010/2011).

Wikis have proven to be successful tools for developing collaborative learning as well as writing skills (Lee, 2010). The wiki

\section{6}


environment seems to benefit collaborative writing and promote successful revision behavior. Peer collaboration and scaffolding fostered attention to form for the improvement of language accuracy in Lee (2010). However, the results are not congruent. Students in Dishaw, Eierman, Iversen \& Philip (2011) found that word and email combination are more useful and easier to use than the wiki environment in completing the project. Furthermore, there was no perceived difference in the effort of collaboration between the two methods.

Wikis have been used in higher education in a variety of ways. They have been used for collaborative learning and collaborative writing (Martinez-Carrillo and Pentikousis, 2008; Matthew, Felvegi and Callaway, 2009; Lee, 2010; Su and Beaumont, 2010; Lin and Yang, 2011; Lin and Yang, 2011), online collaboration (Su and Beamont, 2010) and in assignments and/or projects (Baert, 2008; Allsop,2011; Dishaw, Eierman, Iversen \& Philip, 2011; Bravo and Young, 2011; Witney and Smallbone, 2011).

Although there is a great number of studies conducted on the use of wikis, few have been conducted in the Arab world due to its novelty. Besides, research results are not consistent though most of them seem to favor wikis to other traditional ways. According to review of literature, the need for additional research focusing on the uses of wikis in education, particularly when instructors assign and assess specific collaborative tasks is required in the Arab world.

In this paper the researchers consider remote yet close collaboration where group members perform part of collaborative writing in the classroom and part over the internet and contrast it to collaboration that happens fully face-to-face in the classroom.

Self-regulated learning is a process in which learners actively participate in their own learning in terms of metacognition, motivation and action. Students who can conduct self-regulated learning, have a clear idea of how and why a specific selfregulatory strategy should be employed. They are active learners in terms of metacognition, motivation and action control (Cheng, 2011). Self-regulated learning presumes that students who are active and take control of their own learning at any age level or in

\section{7}


any learning situation perform better and achieve better results. Self-regulated learners "... approach education tasks with confidence, diligence, and resourcefulness. They are aware of when they do or do not know something. They seek out information when needed and follow the necessary steps to master it. When they encounter obstacles such as poor study conditions, confusing teachers, or abstruse text books they find a way to succeed" (Zimmerman 1990).

Evidence from literature indicates that self-regulatory strategies may be a key distinguishing characteristic of good learners (Young and Ley, 2005) or leaders (James, 2009). Competent, self-regulated learners are hypothesized to have the knowledge and strategies needed to learn and remember information and to have the skill to effectively apply these resources to specific learning and memory tasks (Peverly et. al. , 2003). More specifically, self-regulated learners are described as:

- "setting specific hierarchical learning goals,

- holding a learning rather than a performance goal orientation,

- having high self-efficacy,

- being intrinsically interested,

- managing to focus on their performance,

- using self-instructional techniques,

- self-monitoring their learning,

- seeking self-evaluation, attributing success or failure to the strategies used rather than their ability,

- having positive self-reactions, and

- showing a high level of adaptivity".(Kerber et. al., 2005:80)

Schraw and Dennison (1994:474-475) see that self-regulated learning is a component of metacognition. To them, self-regulation includes five sub-skills:

-Planning: Setting goals and aims and resources needed before learning.

- Information Management : Ability to use skills and strategies in a specific direction for better and more effective processing of information.

\section{8}


- Monitoring: A person's awareness of the different strategies he/she uses in learning.

-Debugging: The ability to use alternative compensatory strategies to modify understanding and mistakes in performance.

- Evaluation: The ability to analyze performance and effective strategies after learning.

It is worth noting that the aforementioned self-regulated learning strategies are consistent with the writing process where the writer uses these strategies before, during and after writing to manage and monitor the writing process and perform competently on the assigned writing task.

Although some studies have found success in improving students' self-regulated learning with scaffolds and other instructional aids (Azevedo \& Cromley, 2004), there is little empirical evidence as to whether students will be able to perform certain skills if they are trained to regulate their learning since literature shows congruent results. Peverly et. al. (2003) pinpoints that college students are not good at self-regulation. Too few learners are skilled at regulating their learning to optimize what they learn (Azevedo \& Cromley, 2004). Besides, there is no study, to the best of the researcher's knowledge that dealt with the effect of using Web 2 tools such as wikis on self-regulated learning skills. This study is an attempt to fill in this gap by investigating the effect of using wikis on collaborative essay writing and selfregulated learning skills.

\section{Problem of the Study}

The area of e-learning is new and the studies conducted to investigate the effect of the different potentials e-learning provides are scare compared to other areas of research. Web 2.0 offers great new potentials that were not available before it existed. Web 2.0 offers potentials for synchronous as well as asynchronous collaboration between the internet users. The value of such social activities are appreciated and recognized by some studies but still need more investigation.

\section{9}


Studies in the Arab world are still in their beginning. Most of the studies conducted in the Arab world were conducted on free learning management systems. Very few studies were conducted on commercial learning management systems such as the Blackboard due to its high cost. Since King Khaled University provides free subscriptions to the staff members working for it, a study examining one of the potential it provides, wikis, would be possible. This study investigates the effect of using wikis and face-to face collaborative writing on the writing performance and self-regulated learning skills among EFL learners at the college of education. The study is an attempt to answer the following questions:

1. What is the effect of using wikis and face-to-face collaborative writing on the essay writing performance among EFL students at the college of education?

2. What is the effect of using wikis and face-to - face collaborative writing on self-regulated learning skills among EFL students at the college of education?

This question is divided into the following sub-questions:

a) What is the effect of using wikis and face-to - face collaborative writing on planning for writing skill among EFL students at the college of education?

b) What is the effect of using wikis and face-to - face collaborative writing on information management skill among EFL students at the college of education?

c) What is the effect of using wikis and face-to - face collaborative writing on monitoring and control skill among EFL students at the college of education?

d) What is the effect of using wikis and face-to - face collaborative writing on debugging skill among EFL students at the college of education?

e) What is the effect of using wikis and face-to - face collaborative writing on evaluation skill among EFL students at the college of education?

f) What is the effect of using wikis and face-to - face collaborative writing on the total score of self-regulated learning skills among EFL students at the college of education? 


\section{Hypotheses of the Study}

1. There are no statistically significant differences between the mean scores of the experimental and the control groups in the writing performance.

2. There are no statistically significant differences between the mean scores of the experimental and the control groups in the planning for writing skill.

3. There are no statistically significant differences between the mean scores of the experimental and the control groups in the information management skill.

4. There are no statistically significant differences between the mean scores of the experimental and the control groups in the monitoring and control skill.

5. There are no statistically significant differences between the mean scores of the experimental and the control groups in the debugging skill

6. There are no statistically significant differences between the mean scores of the experimental and the control groups in the evaluation skill

7. There are no statistically significant differences between the mean scores of the experimental and the control groups in the self-regulated learning total score.

\section{Review of Literature}

Wikis and Learning.

Wikis have been around since 1995 when Cunningham developed the first wiki, WikiWikiWeb. They became hugely popular in 2003 (Karasavvidis, 2010). According to Baert (2008: 26), Ward Cunningham, the creator of the original wiki, called it " the simplest online database that could possibly work". According to him, the word wiki was legitimized after Cunningham visited Honolulu airport where shuttle buses are called "wiki wiki" which means quick in Hawaiian. Wikis are collaborative web-based environments that allow multiple users to easily and quickly contribute content. They are dynamic, constantly changing Web pages where readers become authors and editors (Matthew, Felvegi and Callaway, 2009).

\section{1}


A wiki is a second generation web application ("Web 2") which resembles a regular web site for most visitors. However, the editorial process in a wiki is considerably different from conventional web sites. Users can visit the wiki and read the available material but, in addition, they can edit existing contributions and provide new ones (MartinezCarrillo and Pentikousis, 2008). According to Allsop (2011:130), "a wiki is a website where users can modify any page, by adding content or editing that which already exists". Wikis are popular web sites that allow users to create, publish and share web contents without much programming skill (Changa, Morales-Arroyob and Thanc, 2010/2011).

Karasavvidis (2010) quotes Leuf and Cunningham's (2001:14), definition of a wiki as a "freely expandable collection of interlinked web pages, a hypertext system for storing and modifying information - a database, where each page is easily edited by any user with a forms -capable Web browser client" .

Wiki software enables users to easily and quickly edit web pages using their web browser; they do not need any specialized technical knowledge. The wiki software's editing and graphics tools are basic compared to today's complex and ambitious desktop publishing tools. Settings and preferences are limited; at times what is displayed when editing the page is not the same as what is displayed once the page edits are saved. For example, uniform indentations and line spaces may not be uniform once the page is saved (Matthew, Felvegi and Callaway,2009).

In group work, wikis offer students the advantage of most virtual learning environments, such as flexibility and the convenience of not having to meet regularly. Of particular interest for the assessment of individual participation and group processes is the function that tracks activity and stores previous versions (Witney and Smallbone, 2011).

According to Martinez-Carrillo and Pentikousis (2008) the production and acquisition of language in wikis transcend the individual and mentalistic approach to language acquisition as they enable activities that involve multiple voices and give a more goal oriented collective focus. Besides, the environment of the wiki provides resources for taking on complex problems,

\section{2}


supporting language production, and making possible to trace individual contributions as well as aggregated output over time.

Wikis have two states: read and edit. In the read state, they look like a normal page and wikis are in read state by default. When the user wants to edit the page, he/ she must change to the edit state which may require to sign in using a user name and a password in some wikis. When the user clicks the "Edit" button, the raw text is sent to the browser in an editable form so users can modify the content of the page.

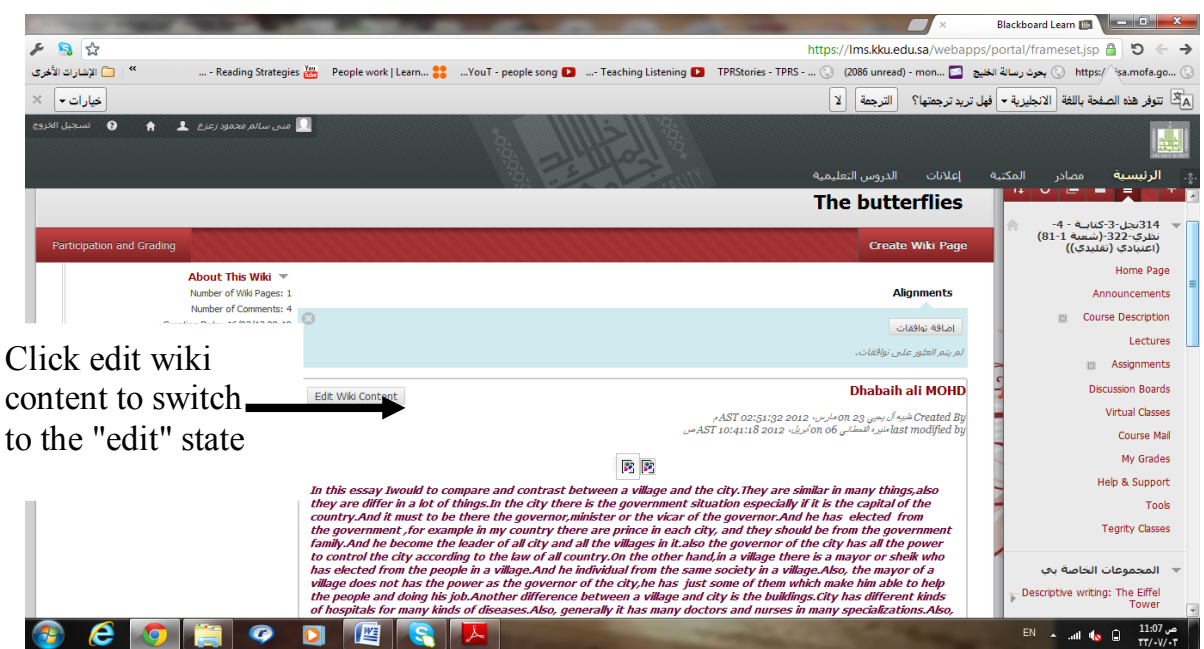

Figure1 : The wiki in the "Read" state

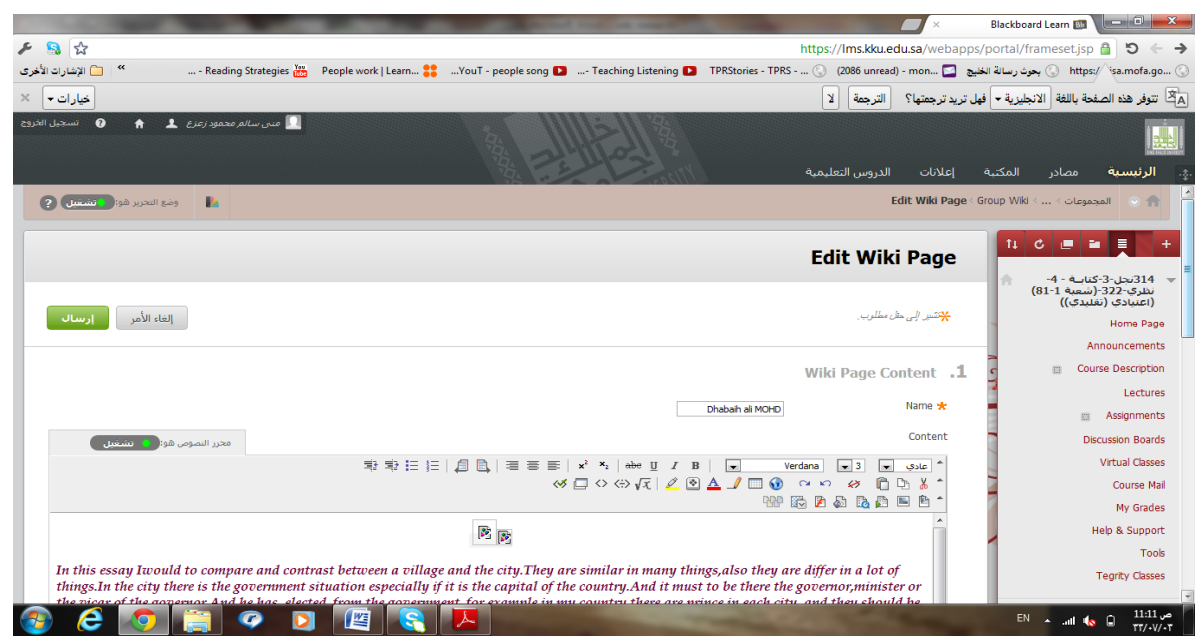

Figure2 : The "Edit" state of the Blackboard wiki

\section{3}

Journal of Arabic Studies in Education \& Psychology(ASEP) 
The wiki participation summary page shows the members contributing to the wiki by presenting the number of modified words and number of page saves.

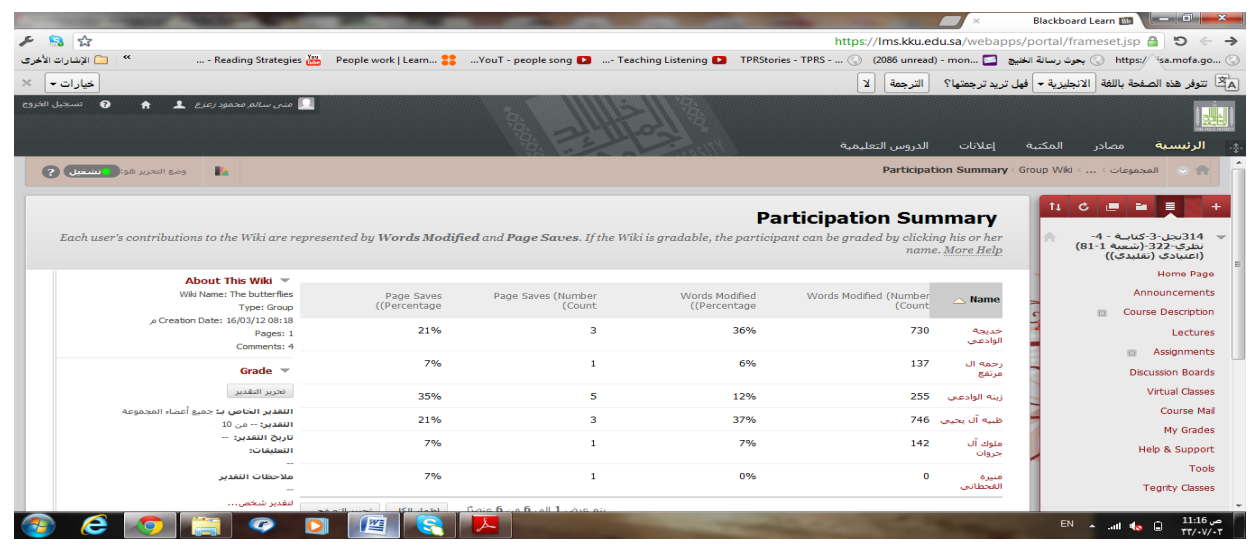

Figure3: Participation summary page of the Blackboard wiki

The wiki also allows deep understanding of the contribution of each member by comparing the versions produced by that specific member to the preceding ones created by herself or by others. Figure (4) shows a participation by the participant Alaa.

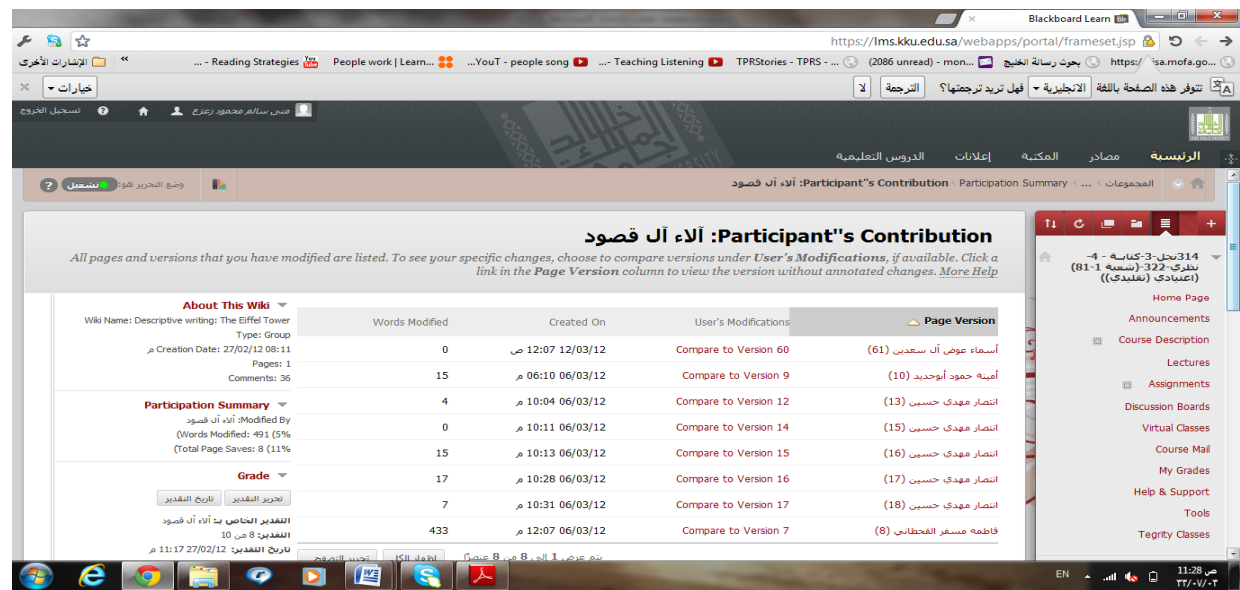

Figure 4: Participant's contribution to the wiki

Another advantage of wikis is that they allow revising the history, comparing different versions created by the participants and tracking the changes with the help of the legend that the wiki provides.

\section{4}




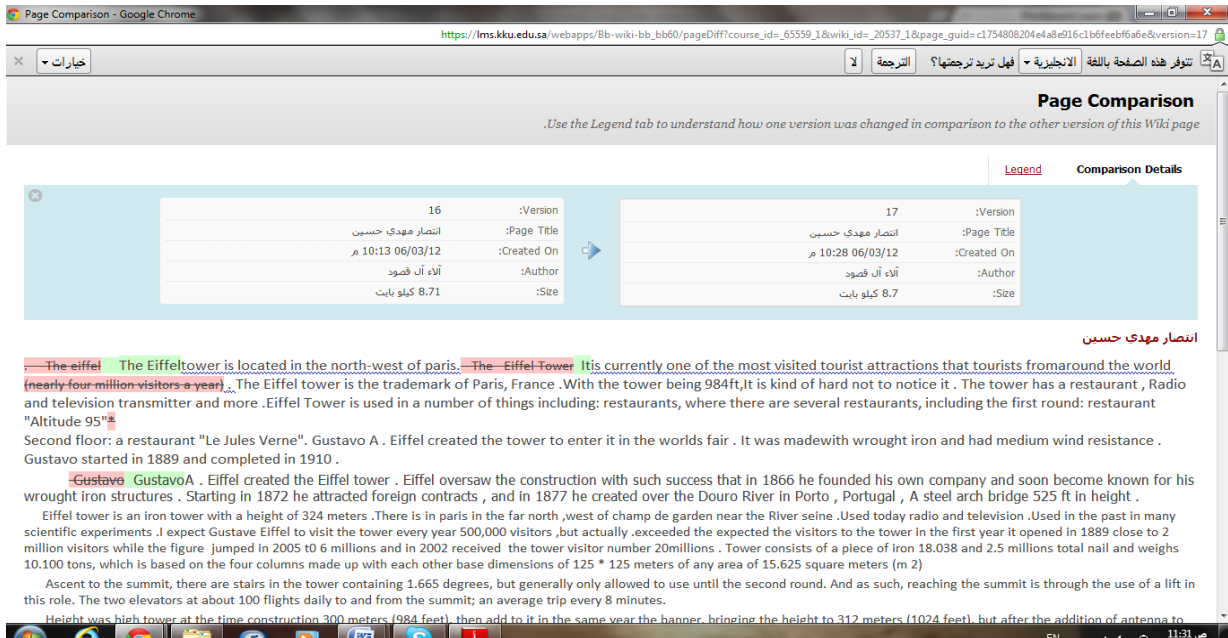

F)

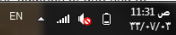

Figure5. Page comparison for tracking changes created by a participant in two versions: 16 and 17

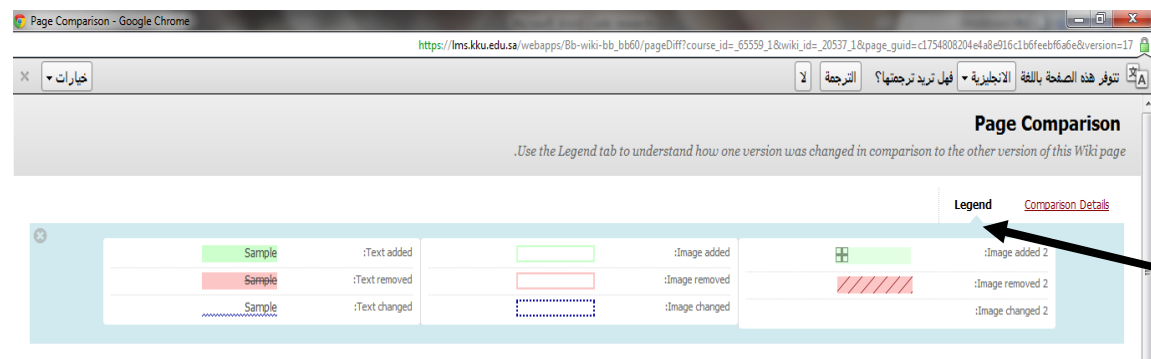

انتصار مهدي حسبن

The eiffet The Eiffeltower is located in the north-west of paris. The Eiffel Towrer Itis currently one of the most visited tourist attractions that tourists fromaround the world fmearly four million visitters a veat). The Eiffel tower is the trademark of Paris, France. With the tower being $984 \mathrm{ft}$, It is kind of hard not to notice it. The tower has a restaurant, Radio and television transmitter and more .Eiffel Tower is used in a number of things including: restaurants, where there are several restaurants, including the first round: restaurant "Altitude $95^{\text {"*x }}$

Second floor: a restaurant "Le Jules Verne". Gustavo A. Eiffel created the tower to enter it in the worlds fair . It was madewith wrought iron and had medium wind resistance. Gustavo started in 1889 and completed in 1910

Gustave GustavoA. Eiffel created the Eiffel tower. Eiffel oversaw the construction with such success that in 1866 he founded his own company and soon become known for his wrought iron structures . Starting in 1872 he attracted foreign contracts, and in 1877 he created over the Douro River in Porto , Portugal , A steel arch bridge $525 \mathrm{ft}$ in height .

Eiffel tower is an iron tower with a height of 324 meters. There is in paris in the far north, west of champ de garden near the River seine. Used today radio and television. Used in the past in many scientific experiments. I expect Gustave Eiffel to visit the tower every year 500,000 visitors, but actually. exceeded the expected the visitors to the tower in the first year it opened in 1889 close to 2 million visitors while the figure jumped in 2005 t0 6 millions and in 2002 received the tower visitor number 20 millions. Tower consists of a piece of iron 18.038 and 2.5 millions total nail and weighs 10.100 tons, which is based on the four columns made up with each other base dimensions of $125 * 125$ meters of any area of 15.625 square meters ( $m$ 2)

Ascent to the summit, there are stairs in the tower containing 1.665 degrees, but generally only allowed to use until the second round. And as such, reaching the summit is through the use of a lift in

this role. The two elevators at about 100 flights daily to and from the summit; an average trip every 8 minutes.

Height was high tower at the time construction 300 meters (984 feet), then add to it in the same year the banner, bringing the height to 312 meters (1024 feet), but after the addition of antenna to

broadcast on its summit, the height of the tower the total 324 meters (1063 feet). has was considered one of the tallest huildings in the world. hut it is no longer the case now.

\section{(4) E S D D D 国 S A}

Figure6. Page comparison for tracking changes created by a participant showing the legend

The application of wikis in educational settings, and especially in language learning, has grown in the last few years and has been researched in a number of recent studies. The

\section{5}


studies varied in scope and area of research and their results were not consistent.

Some studies revealed negative results concerning the effect of wikis on different variables . Dishaw, Eierman, Iversen \& Philip (2011) examined two approaches for supporting students' collaborative report writing: Microsoft Word with Track Changes combined with e-mailing and wikis. Results showed that students preferred the first to the latter. No differences concerning perceived effort of collaboration between the two methods were found. Witney and Smallbone (2011) explored how full-time undergraduate students used wiki to support group assignments. Results showed that students preferred face-to-face collaboration to that through wikis.

There have been many studies that investigated the effect of wikis on different variables revealing positive effects. MartinezCarrillo and Pentikousis (2008) used wikis available in wikispaces for mediated collaborative learning of Spanish as a second language. Results of the study showed that wiki supported the shift from individual to collaborative writing effectively as indicated by a change from (a) personal to collective responsibility; (b) fragmentary and individual comprehension to general and collective knowledge; and (c) mono-contextuality to polycontextuality.

Using qualitative analysis, Allsop (2011) explored 29 a year 5 class of children aged 9-10 years old collaborative behavior while working in wikis. Results indicated that children worked collaboratively in many ways while using wikis for their projects. Besides, they enhanced communication among the group members.

In a case study, Su and Beaumont (2010) explored the extent to which a wiki has facilitated students' online learning and analyzed and evaluated essential aspects for the successful deployment of a wiki in a higher education setting using Salmon's five-stage e-learning framework. Results of the study revealed that a wiki can promote effective collaborative learning and confidence in formative self and peer assessment by facilitating

\section{6}


rapid feedback, vicarious learning through observing others' contributions and easy navigation and tracking facilities. Matthew, Felvegi and Callaway (2009) investigated how the use of class wiki affected the learning of pre-service teachers enrolled in a language arts methods class. Results indicated that contributing to the class wiki led to a deeper processing of the course content and was personally beneficial to the students in spite of persistent technology challenges.

Other studies investigated the effect of using wikis on the writing skills of different samples. Lin and Yang (2011) investigated whether the use of wikis as a collaborative platform would improve the students' writing skills among 32 sophomore students in an English department at a college in Taiwan. Results indicated that students positively recognized the use of wikis in the writing class although they encountered both functional and psychological obstacles to using the new tools, indicating the need to alter their traditional learning practices to embrace new, technology-enhanced learning systems.

In a case study, Lee (2010) used wiki pages over a period of 14 weeks in a beginning writing class at the university level. Using group wiki pages, surveys and interviews, she investigated the effect of wiki use on the participants' writing and factors affecting it. Results showed that wikis helped learners organize content and enhanced peer correction and feedback.

Kost (2011) investigated the use of wikis in collaborative writing projects. Participants used a variety of strategies in the planning, writing and revision phases of their essays. They also achieved a very high success rate in correcting the formal mistakes they detected by pooling their knowledge about language issues. The students enjoyed working collaboratively as they could share ideas and work with each other's strengths, and they also liked the accessibility of the wiki.

Some studies focused on exploring the challenges, barriers or potentials that affect the implementation of wikis. Using qualitative and quantitative data, Karasavvidis (2010) explored the barriers to successful implementation of 38 university students.

\section{7}


Results of the study revealed seven major problems: time and effort required, the task demands, plagiarism, lack of communication, wikis sometimes reflected competition than collaboration, validity of interpretations, and reluctance to edit texts. Woo, Chu, Ho \& $\mathrm{Li}$ (2011) explored the challenges and potential benefits of a wiki for students and teachers in a primaryfive English-language class in Hong Kong. The study found that the use of a wiki in a class of primary-five students in a Chinese primary school where English is taught as a second language (L2) was perceived positively. Students enjoyed using the wiki, and the overall perception was that it helped foster teamwork and improved writing. The tracking functionality of the wiki gave indepth information about the types of edits the students were making and helped the teacher to provide necessary support and feedback, scaffolding their editing process.

Another trend in the wiki studies is directed towards investigating the perceptions of different wiki users. Using a qualitative approach, Baert (2008) investigated the perceptions of teacher candidates concerning the usefulness of wikis as an instructional tool to enhance learning through an online five-week collaborative group project. Results showed that wikis facilitated collaboration among group members, improved writing skills and enhanced deeper understanding of one's own ideas as well as others'.

Chang et.al. (2010) investigated how 92 graduate students perceived learning activities facilitated by wikis, and the effectiveness of several roles wikis might play in constructive and collaborative learning using a questionnaire. Students perceived wikis to enhance collaborative knowledge building among students, but it did not contribute much to learning the subject matter although students were more involved in the learning process than with conventional teaching methods.

Bravo and Young (2011) explored prospective and in-service teachers' perceptions and behaviors of public wiki use during a collaborative Wikipedia assignment in a graduate technology and literacy education course. Results indicated that the participants

\section{8}


have a positive experience posting content on Wikipedia. They also explained different ways they can use to integrate wiki use in their K-12 classrooms.

\section{Self-Regulated Learning.}

Self-regulation of learning is a key factor that impacts learners' motivation to achieve. According to Cheng (2011), Zimmerman was the first academic to propose the construct of self-regulated learning in educational psychology in1989. He believes that self-regulated learning is a process in which learners actively participate in their own learning in terms of metacognition, motivation and action in order to be masters of their own learning. Zimmerman and Schunk (2001) and Mason et.al. (2006) posit that self-regulated learning is an active, constructive process whereby learners set goals for their learning and then attempt to monitor, regulate and control their cognition, motivation and behavior in the service of those goals. Self-regulated learning refers to the processes that maintain the cognition, motivation and behavior necessary to achieve intentional goals (Zimmerman, 2000). It is an essential condition for human success and professional achievement. Self-regulated learning is recognized as an important predictor of student academic motivation and achievement ( Zumbrunn, Tadlock and Roberts, 2011), learning performance (Cheng, 2011), online learning (Wang (2010) and leadership (James, 2009). This process requires students to independently plan, monitor, and assess their learning. However, few students naturally do this well.

Zimmerman (1990: 4-5) explains that self-regulated learners approach educational tasks with confidence, elegance and resourcefulness, ... They are aware when they possess knowledge or skill and when they do not,... They proactively seek out information when needed and take the necessary steps to master it, ... When they encounter problems, they find ways to overcome the problems and succeed, ... They see acquisition as a systematic and controllable process and they accept greater responsibility for their achievement outcomes. Thus self-regulated learners may be described as metacognitively, motivationally and behaviorally active learners. Self-regulated learners plan, set goals, organize, self-monitor and self-evaluate . Students monitor and adjust their learning strategies. According to Cheng (2011), monitoring activities include checking the content of study, judging learning difficulties, assessing progress and predicting learning outcomes. Peverly et. al. (2003) report that research suggests that

\section{9}


self- regulation develops slowly and that only college students demonstrate substantial levels of self-regulatory skills and learning.

One popular cyclical model of self-regulated learning discusses three distinct phases: forethought and planning, performance monitoring, and reflections on performance (Zimmerman, 2000). During the forethought and planning phase, students analyze the learning task and set specific goals toward completing that task. In the performance monitoring phase, students employ strategies to make progress on the learning task and monitor the effectiveness of those strategies as well as their motivation for continuing progress toward the goals of the task. In the final reflection on performance phase, students evaluate their performance on the learning task with respect to the effectiveness of the strategies that they chose. During this stage, students also must manage their emotions about the outcomes of the learning experience. These self-reflections then influence students future planning and goals, initiating the cycle to begin again.

Due to the importance of self-regulated learning, many studies have been conducted to investigate its effect. A trend of studies in self-regulated strategy development is investigating the relationship between it and other variables. Unlike previous studies, Pelt (2008) found no significant relationship between selfregulated learning strategies and academic achievement. Results also showed that high achieving students reported using more self-regulated learning strategies and more advanced strategies than low-achieving students. Al-Alwan (2008) also found significant differences among high and low achieving students in self-regulated learning components (intrinsic goal orientation, extrinsic goal orientation, task value, control of learning beliefs, self-efficacy, test anxiety, metacognition self-regulated, and time and study environment management). However, no significant differences in effort- regulation, peer learning, and help-seeking were found.

Wang (2010) examined the relationship among students' characteristics, self-regulated learning, technology self-efficacy, and course outcomes in online learning settings. Results indicated a positive relationship between the variables indicating an effect of self-regulated learning on learning outcomes in an online environment. Chen (2011) investigated effective self-regulated learning strategies in a lecture-led concept learning environment versus a hands-on computer lab learning environment for an

\section{0}


introduction to information systems course. The findings revealed that effort regulation had a positive effect. Cheng (2011) explored the relationship between students' self-regulation ability and their learning performance. The results showed that students' learning motivation, goal setting, action control and learning strategies played a significant role in learning performance.

Some studies investigated the effect of using self-regulated strategy development on different variables. Hoover (2010) investigated the effect of using self-regulated strategy development for persuasive quick writes with four high school students with learning disability. Results indicated an increase in the number of response parts written and increased stability in the number of words written. Schwankl (2011) used self-regulated learning strategy development with instruction in story writing to teach students with learning disability. Results indicated that the students story writing developed both in quantity and quality.

Several researchers have demonstrated the effectiveness of several approaches to regulating students' (with or without learning disabilities) learning in several areas. Results of the studies indicated positive effects of using self regulated learning based strategies in developing the dependent variables under concern. Aguilar (2008) aimed at developing, transferring and adapting self-regulated learning processes. Results indicated that students in the experimental group outperformed those in the control group and that the strategies were transferred and/ or adapted to other disciplines.

Platten (2010) used a self-regulatory framework to investigate the effect of Incremental Rehearsal vocabulary learning strategy by examining the effects of performance -related feedback and strategy modification on vocabulary learning, motivational beliefs and self-regulation processes. Results indicated that providing performance -related feedback and strategy modification information enhanced learning more vocabulary.

In the area of writing, De La Paz (2001) used the strategy "PLAN and WRITE" with SRSD to develop the writing performance of 3 seventh and eighth graders with attention deficit disorders. Mason, Harris and Graham (2002) used two strategies of self regulation (POW and W-W-W, What=2, How=2) for developing story writing of students with learning disabilities. Chalk, Hagan-Burk and Burk (2005) used an SRSD strategy, DARE, with similar participants to develop their writing

\section{1}


competence. Little et.al. (2010) replicated and extended previous research of self-regulated strategy development for developing planning and persuasive writing within a schoolwide positive behavior support model among students with writing difficulties. Results indicated increase in both quality and quantity of persuasive writing.

\section{Method}

Participants. By the beginning of the second term of the academic year 2011/2012, students enrolled in Level 4 in the English section in the College of Education at Dhahran Al-Janoub, King Khaled University registered themselves in two sections using the Blackboard Learning Management System. At the first lecture, the researcher randomly assigned group $1(\mathrm{~N}=34)$ as the experimental group while group $2(\mathrm{~N}=32)$ served as the control group. 33 students from the experimental group and 32 from the control group completed the Scale of Self-Regulated Learning Skills.

Procedures. In the first lecture, course specification was introduced to the students and discussed with them. Tasks required from the students to complete throughout the term were introduced and discussed. Students were told that these tasks will be done in collaborative groups. The problem of getting together for collaborative work outside the classroom was raised by some of the students and supported and approved by others. It is at that time that students in the experimental group were introduced to the experiment through explaining the purpose of the study and how wikis can be used to develop their collaborative writing skills at a distance solving the problem they raised. All the group members welcomed participation in the experiment and believed that the use of wikis would be a good solution for their problem beside the potential development in their collaborative writing skills.

During the second session, the experimental group had the lecture in the E-learning Lab where they had an introductory session on how to use wikis for writing, collaboration, chatting, file sharing, discussion, editing and revising.

Using a quasi-experimental design, the test of essay writing and the Scale of Self-regulated Learning Skills were administered to the experimental and the control groups as pre-tests before starting teaching. They were also administered after finishing teaching the course as post-tests.

\section{2}


Both the experimental and the control groups were taught the material of Writing 4 Course developed by the first researcher for 13 consecutive weeks in which a theoretical background was given to the students concerning the kind of genres (biography, narrative, descriptive, comparison/contrast, opinion and persuasive ) they are going to write about. The next classes were conducted using the process writing approach (planning, drafting, editing and revising). Students collaborated in groups to plan for writing using a pre-writing technique, mostly brainstorming, to brainstorm ideas about the topic they are going to write about. They also searched for information related to the topic when they felt a need for more information. They were then, in the same groups, asked to collaborate to write their first and second draft, then revise and edit the essay. The experimental group used wikis to brainstorm their ideas, write their different drafts, then revise and edit whereas the control group used face-to face collaborative writing. For each essay, students were allowed two weeks to complete and share with the whole group. Groups' essays were checked, scored and feedback was given by the researcher.

In the wiki, each of the pages was to be produced in a collaborative fashion. Students were allowed to select a topic to write about. The freedom to choose the topic within a specific genre allowed for connecting the students' personal interests with the curriculum content.

\section{Tools of the Study.}

Essay writing exam and Rubric for Scoring Comparison/ Contrast Essays. A 60-minutes essay writing exam was prepared by the first researcher. Students were asked to a compare/ contrast essay in which they compare and contrast teachers' use of face-to-face or e-learning. The essay writing exam was submitted to three staff members in the English Language Department at Dhahran AlJanoub College of Education for validity purposes. the test was applied to 15 English language students enrolled in Level 7 at Dhahran Al-Janoub College of Education. A Rubric for Scoring Comparison/ Contrast Essays was designed. The rubric is analytic and deals with scoring students' essays on the use of good opening and introduction, organization (point to-point or whole to whole), development of ideas and supporting details, format (title, introduction, body and conclusion), the use of vocabulary, grammar, punctuation and transition words.

The Rubric for Scoring Comparison/ Contrast Essays was used by the first researcher and a lecturer in the English

\section{3}


Language Department at College of Education, Dhahran AlJanoub separately to score the essays written by the students. Inter-rater reliability coefficient was 91 indicating reliability of the rubric as a tool for scoring the comparison/ contrast essays written by the students.

Scale of Self-regulated Learning Skills. Scale of Self-regulated Learning Skills was prepared by researchers. The scale consists of 51 items formulated in positive statements. The items are distributed to five dimensions representing the self-regulated learning skills presented by Schraw and Dennison's (1994) model, i.e. planning, information management, monitoring, debugging and evaluation. The participants answer the scale by selecting from a four-point-Lickert Scale where 4 represents always, and 1 rarely. Table (1) represents the distribution of the items according to the subskills.

Table (1): Distribution of the items of the Scale of Self-regulated Learning Skills to the sub-skills

\begin{tabular}{|l|c|}
\hline \multicolumn{1}{|c|}{ Variables } & \multicolumn{1}{c|}{ Items } \\
\hline Planning & $1,6,11,16,21,26,31,36,41,46$ \\
\hline $\begin{array}{l}\text { Information } \\
\text { Management }\end{array}$ & $2,7,12,17,22,27,32,37,42,47$ \\
\hline Monitoring & $3,8,13,18,23,28,33,38,43,48$ \\
\hline Debugging & $4,9,14,19,24,29,34,39,44,49$ \\
\hline Evaluation & $5,10,15,20,25,30,35,40,45,50$ \\
\hline
\end{tabular}

To make sure that the Scale is valid, the first version was presented to seven jury members specialized in educational psychology and curricula and methods of teaching at Al-Taif College of Education. They were asked to give their opinion concerning the matching of the scale items to the definition of the skill it measures and suitability of items to the age of the participants. $85 \%$ of the jury members agreed on the suitability of the items with the result that the scale remained as it is without change.

Besides, internal consistency of the scale was calculated after administering the scale to a sample of 55 students enrolled in the sixth level of the English section at the College of Arts, Al-Taif University. Correlations between the items and the scale total score of the dimension to which it belongs was calculated. All correlation coefficients (Appendix1) were significant at 0.01 indicating that the items have high internal consistency. Correlations of the five sub- scales to the scale total score (Appendix 2) also show high internal consistency. Scale reliability

\section{4}


was estimated using alpha Kronbakh coefficient and SpearmanBrown 's split half. Results are as follows.

Table (2): Correlation Coefficients of the Scale of Self-regulated Learning Skills Reliability

\begin{tabular}{|l|r|r|r|r|r|r|}
\hline $\begin{array}{l}\text { Variable } \\
\text { Method }\end{array}$ & Planning & $\begin{array}{r}\text { Information } \\
\text { Management }\end{array}$ & Monitoring & Debugging & Evaluation & $\begin{array}{r}\text { Total } \\
\text { of } \\
\text { skills }\end{array}$ \\
\hline $\begin{array}{l}\text { Alfa- } \\
\text { Kronpak }\end{array}$ & 0.73 & 0.77 & 0.81 & 0.87 & 0.87 & 0.96 \\
\hline $\begin{array}{l}\text { Split-half } \\
\text { (Sperman- } \\
\text { Browen }\end{array}$ & 0.72 & 0.74 & 0.68 & 0.85 & 0.83 & 0.83 \\
\hline
\end{tabular}

Table (2) shows that all the reliability coefficients are very high that it can be said that the scale is highly reliable.

\section{Results}

This study aimed at investigating the effect of using wikis and face-to face collaborative writing on the writing performance and self-regulated learning skills among EFL students in the college of education. The first hypothesis of the study concerning the essay writing performance stated that "there are no statistically significant differences between the mean scores of the experimental and the control groups in the essay writing performance of EFL students in the college of education". Independent sample t-test was used to analyze the results of the essay writing test to judge the validity of the hypothesis. Table (3) presents results related to this hypothesis.

Table (3): Results of the effect of using wiki on the essay writing performance

\begin{tabular}{|l|l|l|l|l|l|l|l|}
\hline \multirow{2}{*}{ Variable } & \multicolumn{2}{|l|}{ Control group (n=32) } & \multicolumn{2}{|l|}{$\begin{array}{l}\text { Experimental group } \\
(\mathbf{n = 3 4})\end{array}$} & d.f & $\begin{array}{l}\text { t- } \\
\text { value }\end{array}$ & Sig. \\
\cline { 2 - 9 } & Mean & Std.Deviation & Mean & Std.Deviation & & \\
\hline $\begin{array}{l}\text { Essay } \\
\text { writing } \\
\text { performance }\end{array}$ & 4.9375 & 1.6052 & 6.0294 & 2.0521 & 64 & 2.397 & 0.01 \\
\hline
\end{tabular}

Table 3 shows that there are statistically significant differences between the mean scores of the experimental and the control groups on the essay writing performance at the 0.01 level of significance in favor of the experimental group.

Concerning the second hypothesis related to the effect of using wikis on self-regulated learning skills among EFL students, the results of this hypothesis will be dealt with in terms of the selfregulated learning skills adopted in this study which include 
planning, information management, monitoring and control, debugging and evaluation. These are presented as subhypothesis. The fist sub-hypothesis on self-regulated learning skills states that " there are no statistically significant differences between the mean scores of the experimental and the control groups in the planning skill". Table 4 presents information on the results of this sub-hypothesis.

Table (4): Results of the effect of using wikis on the planning skill

\begin{tabular}{|c|c|c|c|c|c|c|c|}
\hline \multirow{2}{*}{ Variable } & & Mean & & Std.Deviation & df & t-value & Sig. \\
\hline & Control & Experimental & Control & Experimental & \multirow[b]{2}{*}{63} & \multirow{2}{*}{$8.33 * *$} & \multirow{2}{*}{0.01} \\
\hline Planning & 22.2813 & 32.667 & 5.5894 & 4.4064 & & & \\
\hline
\end{tabular}

Table (4) shows that there are statistically significant differencs at the 0.01 level of significance between the mean scores of the experimental and control groups in the planning for writing skill in favor of the experimental group.

The second sub-hypothesis on the effect of using wikis on self-regulated learning skills stated that "there are no statistically significant differences between the mean scores of the experimental and the control groups in the information management skill". Table (5) presents results related to this hypothesis.

Table (5): Results of the effect of using wikis on information management

\begin{tabular}{|r|r|r|r|r|r|r|r|}
\hline \multirow{2}{*}{ Variable } & \multicolumn{2}{|c|}{ Mean } & \multicolumn{2}{c|}{ Std.Deviation } & df & t-value & Sig. \\
\cline { 2 - 8 } & Control & Experimental & Control & Experimental & \multirow{2}{*}{63} & \multirow{2}{*}{$7.63 * *$} & \multirow{2}{*}{0.01} \\
\hline $\begin{array}{r}\text { Information } \\
\text { management }\end{array}$ & 22.5938 & 31.5152 & 5.0473 & 4.3669 & & & \\
\hline
\end{tabular}

Table (5) shows that there are statistically significant differences at the 0.01 level of significance between the mean scores of the experimental and control groups in the information management skill in favor of the experimental group.

The third hypothesis stated that "there are no statistically significant differences between the mean scores of the experimental and the control groups in the monitoring and control skills". Table (6) presents results related to this hypothesis.

Table (6): Results of the effect of using wikis on the monitoring and control skills

\begin{tabular}{|r|r|r|r|r|r|r|r|}
\hline \multirow{2}{*}{ Variable } & \multicolumn{2}{|c|}{ Mean } & \multicolumn{2}{|c|}{ Std.Deviation } & df & $\begin{array}{r}\text { t- } \\
\text { value }\end{array}$ & Sig. \\
\cline { 2 - 8 } & Control & Experimental & Control & Experimental & \multirow{2}{*}{63} & \multirow{2}{*}{$7.81 * *$} & 0.01 \\
\hline $\begin{array}{c}\text { Monitoring } \\
\text { and control }\end{array}$ & 21.6875 & 30.2424 & 4.6934 & 4.1233 & & & \\
\hline
\end{tabular}


Table (6) shows that there are statistically significant differences at the 0.01 level of significance between the mean scores of the experimental and control groups in the monitoring and control skill in favor of the experimental group.

The fourth sub-hypothesis stated that "there are no statistically significant differences between the mean scores of the experimental and the control groups in the debugging skill". Table (7) presents results related to this hypothesis.

Table (7): Results of the effect of using wikis on the debugging skill

\begin{tabular}{|c|c|c|c|c|c|c|c|}
\hline \multirow[t]{2}{*}{ Variable } & \multicolumn{2}{|c|}{ Mean } & \multicolumn{2}{|c|}{ Std.Deviation } & df & $\begin{array}{c}\text { t- } \\
\text { value }\end{array}$ & Sig. \\
\hline & Control & Experimental & Control & Experimental & 63 & $856 * *$ & 001 \\
\hline Debugging & 21.8438 & 29.6061 & 3.5022 & 3.7909 & & & 0.01 \\
\hline
\end{tabular}

Table (7) shows that there are statistically significant differences at the 0.01 level of significance between the mean scores of the experimental and control groups in the debugging skill in favor of the experimental group.

The fifth sub-hypothesis stated that "there are no statistically significant differences between the mean scores of the experimental and the control groups in the evaluation skill". Table (8) presents results related to this hypothesis.

Table (8): Results of the effect of using wikis on the evaluation skill

\begin{tabular}{|c|c|r|r|r|r|r|r|}
\hline \multirow{2}{*}{ Variable } & \multicolumn{2}{|c|}{ Mean } & \multicolumn{2}{c|}{ Std.Deviation } & df & $\begin{array}{c}\text { t- } \\
\text { value }\end{array}$ & Sig. \\
\cline { 2 - 7 } & Control & Experimental & Control & Experimental & 63 & $7.69^{* *}$ & \multirow{2}{*}{0.01} \\
\hline Evaluation & 22.5625 & 31.5758 & 5.1989 & 4.2207 & & & \\
\hline
\end{tabular}

Table (8) shows that there are statistically significant differences at the 0.01 level of significance between the mean scores of the experimental and control groups in the evaluation skill in favor of the experimental group.

The sixth sub-hypothesis stated that "there are no statistically significant differences between the mean scores of the experimental and the control groups in the self-regulated learning total score". Table (9) presents results related to this hypothesis.

Table (9): Results of the effect of using wikis on the total score of self-regulated learning skills

\begin{tabular}{|c|r|r|r|r|r|r|r|}
\hline \multirow{2}{*}{ Variable } & \multicolumn{2}{|c|}{ Mean } & \multicolumn{2}{c|}{ Std.Deviation } & df & t-value & Sig. \\
\cline { 2 - 8 } & Control & Experimental & Control & Experimental & & & \\
\hline $\begin{array}{c}\text { Total scores of } \\
\text { self-regulated } \\
\text { learning skills }\end{array}$ & 110.9688 & 155.6061 & 21.5549 & 18.3489 & 63 & $9.00 * *$ & 0.01 \\
\hline
\end{tabular}


Table (9) shows that there are statistically significant differences at the 0.01 level of significance between the mean scores of the experimental and control groups in the total score of self-regulated learning skills in favor of the experimental group.

\section{Discussion and interpretation of the results.}

This study aimed at investigating the effect of using wikis and face-to-face collaborative writing on the essay writing performance and self-regulated learning skills among EFL students in the college of education. Results of the study are encouraging showing a positive effect of using wikis on both essay writing and self-regulated learning skills. Students using wikis outperformed those using face- to-face collaborative writing in both variables: essay writing and self-regulated learning skills.

Results of the study are contrary to those revealed by Dishaw, Eierman, Iversen and Philip (2011) and Witney and Smallbone (2011) that reached negative effects of using wikis and whose samples favored face-to-face collaboration to wiki use.

On the other hand, results of the study are consistent with Baert (2008), Martinez-Carrillo and Pentikousis (2008), Su and Beaumont (2010), Allsop (2011), Lee (2010, Kost (2011), Lin and Yang (2011) and Woo, Chu, Ho and Li (2011) showing positive effect of using wikis on communication (Allsop, 2011), collaborative writing (Baert, 2008, Martinez-Carrillo and Pentikousis, 2008 and Kost, 2011), online learning (Su and Beaumont, 2010) and peer correction and feedback (Lee, 2010). As other studies showed, wikis enhanced students writing as students had a chance to collaborate to plan for their writing, brainstorm and exchange, search the internet and add hyperlinks to their essays, revise and edit for each other and comment of each other's ideas. The researchers agree with MartinezCarrillo and Pentikousis (2008) that the prospect of observing the daily growth of their own work, monitoring their group's contributions, and following the gradual development of the whole wiki, proved to be extremely motivational for the majority of the students. Besides, the wiki gives multiple opportunities for language production and participation in many ways (adding text, links, pictures, searching for new information, moderating, editing, and so on).

Wiki users are provided with a good tool which is the ability to track changes in the wiki pages. A detailed analysis of the types of revisions in the wiki's tracking system indicated that the content

\section{8}


of ideas was revised more than the form. This result is in accordance to Woo et al. (2011). This may be due to the fact that technology provide students with spelling checks that may do this task for them. Besides, students may feel at ease with communicating through technology, which tends to produce more content and process discussions. The teacher's instruction focusing on content also played an important role. This may need further investigation through a comparative study to examine what other factors contribute to help produce content revision among the writers.

Furthermore, a wiki is an open-editing tool that is easily accessible online and simple enough for students with different abilities. It may be easily integrated and adapted into other classrooms with appropriate scaffolds to guide students in posting constructive comments and timely teacher feedback. Wiki's tracking system gives in-depth information about the types of edits the students are making and helps teachers assess their collaboration and the development of their group writing process, a task that may be difficult to monitor in traditional group work. This can help teachers decide on the kind of support to be given, and provide immediate feedback when necessary to scaffold the writers during the course of writing and not at the end when the product is finished.

Peer feedback and peer editing is very clear when analyzing the revisions in the tracking system. A future study may be needed to figure out how peer critiquing actually leads to creativethinking skills and subsequently to revisions or new creative ideas.

Concerning collaborative learning, throughout the study, students in both the experimental and the control groups, made favorable comments about working in groups. They found collaborative learning a motivating experience as group members can receive help from their peers, including corrections of their language productions when necessary. Some students noted that working in a team makes it easier to get new ideas. Although this can be often translated into more work, at the same time, it makes such work more meaningful. Students in the experimental group expressed their relief and low level of anxiety finding a way to collaborate and get their essay writing assignment done through the wikis since wikis solved the problem of finding free time to meet the group members to discuss and exchange ideas, revise and edit for each other.

\section{9}


It is worth noting that students in the experimental group reported some challenges and problems reported in other studies (see Karasavvidis, 2010 and Lin and Yang, 2011). The challenges were related to the time and effort needed to complete an essay writing task using wikis compared to face-to-face collaboration. Although the use of wikis does not require technical skills and most students are familiar with using the computer and the internet, another difficulty that faced students in the experimental group was how to use wikis for exchanging ideas and files, posting new information, modifying and editing text . Some students reported having a hard time coping with the use of wikis for essay writing purposes. However, after three weeks, students started to be familiar with wiki use and complaints concerning its use were very few.

Another idea of great concern is that some students felt more comfortable when working alone and reported this feeling. They have been taught in an educational system that rewarded and encouraged individual achievement. Besides, those students have some personal traits that hinder them from participation in collaborative work. Those students usually resisted collaborative work and their participation was limited as Karasavvidis (2010) reported. In situations like these, evaluation can be an excellent tool making students understand that, because of the collaborative nature of the task, the evaluation unit will be the group and not the individual. A study that investigates the effect of personal traits of participation in online collaborative activities may be required. Another suggestion is to compare the effect of collaboration vs. individual work on the writing performance of EFL students.

The researchers agree with Karasavvidis (2010) that the use of wikis as one Web 2.0 tools requires a major epistemological shift on the part of the students. As opposed to traditional, face-toface teaching, e-learning using Web 2.0 tools requires the learners to be active and cooperative not empty pots receiving what teachers have already prepared for them.

Throughout the study, students in the experimental group reported that shared editing is a difficult complex process. A study investigating the editing behaviors of EFL students using wikis for collaborative writing at the secondary and the tertiary level would provide insights on good and bad practices that might be of great importance to the area of wiki use for writing. Another study would

\section{0}


be needed to investigate and compare/ contrast the collaborative writing behavior of good and bad essay writers using wikis.

As for self-regulated learning skills, results of the study show that the use of wiki for collaborative writing enhanced the EFL students self-regulated learning skills: planning, information management, monitoring and control, debugging and evaluation as well as in the total score of self-regulated learning skills. These results may be attributed to the fact that this study adopted a process- writing approach to writing which moves from planning to actual writing of different drafts and finally editing and revision. These steps indirectly tackle the self-regulated learning skills. Students moved from setting goals for the writing task to planning for it by brainstorming , quick-writing, free writing, word mapping or outlining, to searching for information and writing the different drafts. While writing, students monitor and control their writing. finally, students revise and edit their essay using the selfevaluation checklist given for them with each genre they write on (biography, similarity/contrast, descriptive, opinion or argumentative).

Results of the study are consistent with De La Paz (2001), Mason, Harris and Graham (2002), Aguilar (2008), Hoover (2010), Little et.al. (2010), Platten (2010), Chen (2011), Cheng (2011) and Schwankl (2011) found positive effects of instruction in selfregulated learning on performance in different variables.

This study is important since it deals with two variables of great importance, i.e. the use of wiki for writing through and selfregulated learning skills. It is important to mention that selfregulated learning skills help learners become better and more effective writers. When students are equipped with self-regulated learning skills, writing becomes easier and more comfortable. Results of studies show that self-regulated learning skills increased both quantity and quality of writing among learners with learning disabilities (Schwankl, 2011 and Hoover, 2010) not to mention students without learning disabilities.

This study used wikis for developing collaborative writing which indirectly developed self-regulated learning skills. A study may be required to investigate the effect of using wikis for developing collaborative writing with direct instruction in selfregulated learning skills.

Self-regulated learning skills can be assessed using aptitude- based or event-based measures (Platten, 2010). By

\section{1}


focusing on self-regulation as a stable trait, aptitude - based measures are unable to assess the immediate effects of specific learning events. Conversely, event- based measures of selfregulation focus on its occurrence contingency and patterned contingency. Self-regulated learning skills in this study were evaluated using a questionnaire developed by the researchers, a study evaluating self-regulated learning skills through event-based measures or a micro-analytic assessment methodology relying on context- specific open- and closed- questions at key points during performance of specific learning may yield different results and may shed more in-depth light on the development of these skills.

It is important to emphasize that self regulated learning does not only help students to know about writing and the writing process, it also helps students to manage, monitor and evaluate this process. Self-regulated learning also distinguishes high from low achievers as supported by Pelt (2008) and Al-Alwan (2008). Students should be directly or indirectly introduced to selfregulated learning skills and be allowed to have enough practice in using them to help low achievers acquire the strategies that characterize good achievers. They should also be instructed to use their self-regulatory strategies regularly. Like Schwankl (2011), students in this study were instructed to monitor and evaluate their writing throughout the study. The activities of selfpeer and group correction in addition to the self-evaluation checklists provided by the researchers helped develop students' monitoring and evaluation skills.

\section{References}

- Aguilar, A. C. (2008). Developing, transferring, and adapting self-regulated learning processes. Ph.D. thesis, Graduate School: Temple University, ProQuest Dissertations and Theses.

- Al-Alwan, A.F. (2008). Self-regulated learning in high and low achieving students at Al-Hussein Bin Talal University (AHU) in Jordan. International Journal of Applied Educational Studies , 1 (1), 1-13.

- Allsop, Y. (2011). Does collaboration occur when children are learning with the support of a wiki? The Turkish Online Journal of Educational Technology - October 2011, (10:4),130-137.

- Baert, H. (2008). Wiki \& TGFE: A collaborative approach to understanding games education, M.A. thesis, Faculty of Graduate Studies, University of Manitoba.

\section{2}


- Bravo, V. J. and Young, M.F. (2011). The impact of a collaborative Wikipedia assignment on teaching, learning and student perceptions in a teacher education program. Canadian Journal of Learning and Technology. (37:3), 1-24.

- Chang,Y. M.; Miguel, A.; Than, H.; Tun, Z. and Wang, Z. (2010/2011). Collaborative learning in wikis. Education for Information, 28 (2010/2011) 291-303.

- Chen, C.N. (2011). Self-regulated learning strategies and achievement in an Introduction to Information System Course. Information Technology, Learning, and Performance Journal, 20 (1), 11-25.

- Cheng, E. C. K. (2011). The role of self-regulated learning in enhancing learning performance, The International Journal of Research and Review, 6 (1), 1-16.

- De La Paz, S. (2001). Teaching writing to students with attention deficit disorders and specific language impairment. The Journal of Educational Research, 95:1, 37-47.

- Dishaw, M., Eierman, M. A., Iversen, J. H. \& Philip, G. C. (2011). Wiki or word? Evaluating tools in collaborative writing and editing. Journal of Information Systems Education, 22(1), 34-54.

- Hoover , T.M. (2010). Effects of self-regulated strategy development on writing for high school students with learning disabilities. P.h. D. thesis, The Pennsylvania State University, The Graduate School, College of Education.

- Karasavvidis, I. (2010). Wiki uses in higher education: exploring barriers to successful implementation . Interactive Learning Environments. Vol. 18, No. 3, September 2010, 219-231.

- Kost, C. (2011). Investigating writing strategies and revision behavior in collaborative wiki projects, CALICO Journal, 28(3), 606-620.

- Kovacic, A., Bubas, G.and Zlatovic,M. ( 2007). Evaluation of activities with a wiki system in teaching English as a Second Language. Retrieved:

25/2/2012. Available:http://www.leonardolets.net/ict/common/download/AndrejaKovacic.pdf

\section{3}


- Kovacic, A.; Bubas, G.;and Zlatovic, M.(2008). E-tivities with a Wiki: Innovative Teaching of English as a Foreign Language. Retrieved: 25/2/2012. Available: http://eunis.dk/papers/p87.pdf

- Lee, L. (2010). Exploring Wiki-Mediated Collaborative Writing: A Case stusy in an Elementary Spanish Course. CALICO Journal, (27:2), 260-276.

- Lin, W. and Yang, S. C. (2011). Exploring students' perceptions of integrating Wiki technology and peer feedback into English writing courses. English Teaching: Practice and Critique, July, 2011, Volume 10, Number 2, 88-103.

- Little, M.A.; Lane, K.L.; Harris, K.R.; Graham, S.; Story, M. and Sandmil, K. (2010). Self-regulated strategies development for persuasive writing in tandem with schoolwide positive behavioral support: Effects for second-grade students with behavioral and writing difficulties. Behavioral Disorders, 35 (2), 157- 197.

- Martinez-Carrillo, C. and Pentikousis, K. (2008). An Application of wikis for mediated collaborative learning to Spanish L2. in Proc. International Conference on Internet and Multimedia Systems and Applications (EurolMSA), Innsbruck, Austria, March 2008, pp. 39-44. Retrieved 27/4/1433. Available: http://ipv6.willab.fi/kostas/WikiSpanishL2-errata.pdf

- Matthew, K. I.; Felvegi, E. and Callaway, R. A. (2009). Wiki as a Collaborative Learning Tool in a Language Arts Methods Class. Journal of Research on Technology in Education. 42(1), 51-72.

- Pelt, J. (2008). The relationship between self-regulated learning and academic achievement in middle school students: A crosscultural perspective. Ph.D. thesis, College of Education, Department of Educational Studies, University of South Carolina, ProQuest Dissertations and Theses.

- Peverly, S.T.; Robert, K. E.; Graham, M. and Show, R. (2003). College adults are not good at self-regulation: A study on the relationship of self-regulation, note taking and test taking. Journal of Educational Psychology, 95:2, 335-346.

- Platten, P. (2010). Initiation of the self-regulated feedback loop: The effects of feedback and strategy modification on vocabulary learning, motivational beliefs and self-regulation

\section{4}


processes. Ph. D. thesis, The University of WisconsinMilwaukee, ProQuest Dissertations and Theses.

- Schraw, G., and Dennison, R. S. (1994). Assessing Metacognitive Awareness. Contemporary Educational Psychology, 19, 460-475.

- Schwankl, J.L. (2011). Self-regulated strategy development: Effects on writing of students with learning disabilities. Action research project, Southwest Minnesotta State University, ProQuest Dissertations and Theses.

- Su, F. and Beaumont, C. (2010). Evaluating the use of a wiki for collaborative learning, Innovations in Education and Teaching International, 47 (4), 417-431.

- Witney, D. \& Smallbone, T. (2011). Wiki work: Can using wikis enhance student collaboration for group assignment tasks? Innovations in Education and Teaching International, 48 (1), 101-110. DOI: 10.1080/14703297.2010.543765

- Woo, M., Chu, S., Ho, A., \& Li, X. (2011). Using a Wiki to Scaffold Primary-School Students' Collaborative Writing. Educational Technology \& Society, 14 (1), 43-54.

- Zimmerman, B. J. (1990). Self-regulated learning and academic achievement: An overview. Educational Psychologist, 25, 3-17.

- Zimmerman, B. J. (2000). Attaining self-regulation: A social cognitive perspective. In M. Boekaerts, P.R. Pintrich, and M. Zeider (Eds.), Self-regulation: Theory, research, and applications (pp. 13-39). Orlando, FL: Academic.

\section{潘潾潾潘洸}

